\title{
Ozonioterapia em procedimentos estéticos
}

Daniela Lopez ${ }^{1}$

daniela.1opezz@hotmail.com

\section{RESUMO}

A ozonioterapia é uma terapia realizada por meio da administração do ozônio no corpo, o gás é composto por 3 átomos de oxigênio (O3) e tem como objetivo de auxiliar na oxigenação dos tecidos, afim de aumentar a resposta do sistema imunológico, ajudando nas doenças infecciosas. Sendo assim, o objetivo do presente estudo é compreender as evidências cientifícas da técnica de ozonioterapia nas disfunções estéticas. Trata-se de uma revisão de literatura no portal de periódicos eletrônicos da SciELO, PubMed e Science Direct. É considerada uma técnica segura que não traz danos a saúde dos indivíduos e é comumente utilizada para tratar diversas disfunções: estéticas e médicas.

Palavras chaves: ozônio; ozonioterapia; disfunções estéticas; rejuvenescimento; estrias; psoríase; dermatite

\footnotetext{
${ }^{1}$ Graduada em estética e cosmetologia,Pós graduada em procedimentos intradérmicos e subcutâneos, Especialista em Cosmiatria Orgânica e Ortomolecular, Presidente da sociedade brasileira de estética e cosmetologia, Pós graduada em biomedicina estética, Pós graduanda em Estética e Cosmetologia Avançada UNIFESP - Universidade Federal de São Paulo, Residência em Intradermoterapia Estética T.A.E Pesquisadora em cosmetologia em prol do Envelhecimento, curso integrado a UNICAMP. Autora do Livro a História da Legislação da Estética e Cosmetologia no Brasil.
} 


\title{
Ozone therapy in aesthetic procedures
}

\begin{abstract}
Ozone therapy is a therapy performed through the administration of ozone in the body, the gas is composed of 3 oxygen atoms (O3) and aims to assist in tissue oxygenation, in order to increase the immune system response, helping in diseases infectious diseases. Therefore, the aim of this study is to understand the scientific evidence of the ozone therapy technique in aesthetic dysfunctions. This is a literature review on the SciELO, PubMed and Science Direct electronic journal portal. It is considered a safe technique that does not harm the health of individuals and is commonly used to treat various disorders: aesthetic and medical.
\end{abstract}

Keywords: ozone; ozone therapy; aesthetic dysfunctions; rejuvenation; stretch marks; psoriasis; dermatitis

Artículo recibido: 10 Setiembre. 2021 Aceptado para publicación: 15 Octubre. 2021 Correspondencia: daniela.lopezz@hotmail.com Conflictos de Interés: Ninguna que declarar 


\section{INTRODUÇÃO}

\subsection{Ozonioterapia}

É umaTerapia realizada por meio da administração do ozônio no corpo. O gás é composto por 3 átomos de oxigênio (O3), e tem como objetivo auxiliar na oxigenação dos tecidos, afim de aumentar a resposta do sistema imunológico, ajudando nas doenças infecciosas como feridas infectadas ou HIV, e no alivio da dor crônica devido à artrite reumatóide ou fibromialgia, por exemplo (Zeng, 2018).

A técnica teve início na Alemanha e na União Soviética durante a primeira guerra mundial, se dissipando pela Europa, China e América (Zeng, 2018).

O mecanismo de ação do ozônio não é totalmente conhecido, isso porque os usuários da técnica, se preocupam principalmente em conhecer a dose terapêutica sem buscar entender como o ozônio atua no sistema biológico (Zeng, 2018).

O ozônio fisicamente se dissolve em água pura, e em garrafa de vidro bem fechada o ozônio fica ativo durante dias. Em contrapartida, quando entra em contato com o oxigênio, é dissolvido em água biológica (solução fisiológica, plasma, linfa, urina) fazendo com que o ozônio reaja imediatamente (Tirelli, 2019).

Quando penetra o organismo, por meio da pele e/ou mucosas, permanece nas células, devido ao fato de após a aplicação, o ozônio deixa de existir. Reagindo em conjunto aos ácidos graxos poli-insaturados, antioxidantes, compostos tióis, como glutationa e albumina, porém isso irá depender da quantidade da dose aplicada, além de reagir com carboidratos, enzimas, DNA e RNA. Sendo assim, o conjunto de tais compostos agem como doadores de elétrons e sofrem oxidação (Tirelli, 2019).

Segundo Anagha et. al. 2016, exitem três mecanismos de ação da ozonioterapia. Sendo o primeiro, relacionado à inativação de micro-organismos. Nas bactérias ocorre a interrupção da integridade do envelope celular por meio da oxidação dos fosfolipídios e lipoproteínas. Já nos fungos, o ozônio consegue inibir o crescimento celular. Nos vírus, promove uma lesão no capsídeo viral e perturba o ciclo reprodutivo, pois interrompe o contato vírus-célula com a peroxidação.

A segunda hipótese, é de que ocorre uma ligação ao estímulo do metabolismo do oxigênio. Promovendo aumento na taxa de glicólise dos glóbulos vermelhos, elevando a estimulação do 2,3-difosfoglicerato, consequentemente levando ao aumento na quantidade de oxigênio liberado para os tecidos. Gerando assim, a estimulação da 
produção de enzimas que atuam como sequestrantes de radicais livres e protetores da parede celular, e de vasodilatadores, como por exemplo a prostaciclina (Anagha, 2016). O terceiro, é devido à ativação do sistema imunológico. Quando ocorre a aplicação em concentrações entre 30 e $55 \mu \mathrm{g} / \mathrm{mL}$ aumenta a produção de interferon, diminuindo o fator de necrose tumoral e de interleucina-2, diminuindo a intensidade das reações imunológicas subsequentes (Anagha, 2016).

Para os tratamentos de osteoartrose, atua ativando no metabolismo celular, induzindo a síntese de enzimas antioxidantes e na redução da síntese de prostaglandinas, melhorando as funções do sistema redox diminuindo o estresse oxidativo, e consequetimente aumentando o aporte de oxigênio tecidual através de ação hemorreológica, vasodilatação e estímulo angiogênico (Tirelli, 2019).

\subsection{Ozonioterapia em procedimentos estéticos}

Como é uma técnica versátil, pode ser utilizado para diversos tratamentos; como as disfunções estéticas. Podendo ser usados de maneira tópica, através de bolsas plásticas, óleos ou água ozonizados, bem como por meio das aplicações por injeções (Grillo, 2021). Quando o gás entra em contato com o organismo, estimula o sistema imunológico, ativa a circulação através do óxido nítrico, oxigenação tecidual, nutrição. Auxília na liberação de fatores de crescimento, estimulando assim a regeneração do tecido, possui ação antioxidante com efeitos anti-fungos, bactérias e vírus (Grillo, 2021).

Possuí ação lipolítico, auxiliando nos tratamentos de gordura localizada, regulam funções dos rins, fígado e tireoide. Na atuação contra as varizes, é utilizado devido ao fato de estimular a circulação de maneira rápida (Pederzoli, 2021).

Podendo ser usado nos demais tratamentos como: rejuvenescimento da pele e tratamento de hipercromias, combate de acne e da queda capilar, tratamento contra flacidez da pele e papada, proteção e rejuvenescimento facial, eliminação de celulite, estrias e gordura localizada (Pederzoli, 2021).

\section{OBJETIVO}

- Compreender as evidências cientifícas da técnica de ozonioterapia nas disfunções estéticas.

\section{MÉTODOS}

Trata-se de uma revisão de literatura no portal de periódicos eletrônicos da SciELO, PubMed e Science Direct. Sendo utilizado os seguintes termos para realização da busca 
de dados em português: ozônio, ozonioterapia, disfunções estéticas, rejuvenescimento, estrias e em inglês: ozone, ozone therapy, aesthetic dysfunctions, rejuvenation, stretch marks.

\section{RESULTADOS E DISCUSSÃO}

A revisão foi construída por 5 estudos entre eles, 1 ensaio clínico, 3 pré-clínicos e diferentes métodos de avaliação.

Tabla 1.

\begin{tabular}{|c|c|c|c|c|c|}
\hline $\begin{array}{l}\text { Autor } \\
\text { (ano) }\end{array}$ & $\begin{array}{l}\text { Tipo de } \\
\text { estudo }\end{array}$ & Amostra & $\begin{array}{l}\text { Tipo de } \\
\text { terapia }\end{array}$ & Objetivo & Análises \\
\hline $\begin{array}{l}\text { Xiao et. } \\
\text { al. }(2017)\end{array}$ & Pré-clínico & $\begin{array}{l}12 \text { Camundongos } \\
\text { fêmeas } \\
\mathrm{N}=6 \text { controle e } \\
\mathrm{n}=6 \text { em tratadas }\end{array}$ & Óleo ozonizado & $\begin{array}{l}\text { Reparação } \\
\text { tecidual }\end{array}$ & $\begin{array}{l}\text { Colágeno I, } \alpha \text {-SMA e TGF- } \\
\beta 1 \text { Níveis de mRNA e } \\
\text { proteínas em fibroblastos, } \\
\text { transição } \\
\text { mesenquimal (EMT) }\end{array}$ \\
\hline $\begin{array}{l}\text { Zeng1 et. } \\
\text { al. (2020) }\end{array}$ & $\begin{array}{l}\text { Ensaio } \\
\text { clínico }\end{array}$ & $\begin{array}{l}30 \text { homens e } \\
\text { mulheres }\end{array}$ & $\begin{array}{l}\text { Aplicação de } \\
\text { ozonioterepia } \\
\text { em injeções }\end{array}$ & $\begin{array}{l}\text { Dermatite } \\
\text { atópica }\end{array}$ & $\begin{array}{l}\text { Escores SCORAD, células } \\
\text { inflamatórias nas lesões de } \\
\text { DA, proporção de S. aureus }\end{array}$ \\
\hline $\begin{array}{l}\text { Zeng2 et. } \\
\text { al. (2020) }\end{array}$ & Pré-clínico & $\begin{array}{l}10 \text { Camundongos } \\
\text { com psoríase }\end{array}$ & $\begin{array}{l}\text { Tópico com } \\
\text { ozônio }\end{array}$ & Psoríase & $\begin{array}{l}\text { Lesões de IMQ, receptor toll- } \\
\text { like } 2 \text { (TLR2), células T, } \\
\text { citocinas }\end{array}$ \\
\hline $\begin{array}{l}\text { Gao et. al. } \\
\text { (2020) }\end{array}$ & Pré-clínico & $\begin{array}{l}30 \text { Camundongos } \\
\text { com psoríase }\end{array}$ & Óleo ozonizado & Psoríase & $\begin{array}{l}\text { Proteínas KRT6, IL-17, IL- } \\
\text { 22, KRT10 e Tp63 }\end{array}$ \\
\hline
\end{tabular}

Fonte: Autores

O de Xiao et. al. 2017, demonstrou os efeitos positivos do óleo ozonizado na reparação tecidual, através das análises de colágeno tipo I, $\alpha$-SMA e TGF- $\beta 1$ Níveis de mRNA e proteínas em fibroblastos. Demonstrando um aumento na migração dos fibroblastos, no processo de transição epitelial-mesenquimal (EMT) em fibroblastos via fibronectina, vimentina, N-caderina, MMP-2, MMP-9, proteína de ligação ao fator de crescimento semelhante à insulina (IGFBP) - 3, IGFBP5 e IGFBP6, bem como na diminuição da expressão da proteína E-caderina epitelial e do marcador de senescência celular p16.

No ensaio clínico, onde os voluntários receberam a terapia durante três dias, apresentando resultados na diminuição significativa nos escores SCORAD e infiltração de células inflamatórias nas lesões de dermatite atópica. (Zeng, 2020) 1

Em relação ao ensaio pré-clinico, para tratamento de psoríase, apresentou diminuição significativa no processo de formação de lesões do tipo psoríase induzidas por IMQ e a expressão de fatores inflamatórios associados à psoríase. 
Em relação ao ensaio pré-clínico, para tratamento de psoríase, apresentou diminuição significativa no processo de formação de lesões do tipo psoríase induzidas por IMQ e a expressão de fatores inflamatórios associados à psoríase.

Confirmou que a ativação induzida por IMQ do receptor toll-like 2 (TLR2) / via de sinalização do fator nuclear $\kappa \mathrm{B}(\mathrm{NF}-\kappa \mathrm{B})$ foi significativamente suprimida em lesões semelhantes à psoríase após o tratamento tópico com ozônio (Zeng2, 2020).

O estudo de Gao et. al. 2020, resultou que as proteínas KRT6, IL-17 e IL-22 nas lesões de psoríase diminuíram, enquanto as proteínas KRT10 e Tp63 nas lesões de psoríase aumentaram pelo tratamento com ozônio em tecidos psoriáticos de camundongos IMQ, melhorando, portanto, a psoríase.

\section{CONSIDERAÇÕES FINAIS}

Por meio dos estudos avaliados nesta revisão, é possível compreender os benefícios da ozonioterapia, em diferentes formas de aplicação: por meio de injeções e de maneira tópica. Sendo considerada uma técnica segura, sem trazer danos a saúde dos indivíduos e comumente utilizada para tratar diversas disfunções, estéticas e médicas.

\section{REFERENCIAS}

ANAGHA, V.S., Arun, V.S., Digamber, M.S., Swati, V.P., Mahesh, S.C., Mrinal, V.S., et al. Ozone therapy: healing properties of the blue gas. Int J Oral Health Dentistry. n. 2 , v. 1, págs. $35-8,2016$

da Costa, L. F. P., \& Assunção, V. I. P. OZÔNIOTERAPIA APLICADA A CIRURGIA ORAL. REVISÃO DE LITERATURA.

da Silva, H. M., Oliveira, E. C. M., de Lira, L. M. S. S., Rocha, L. M. B. M., Gaines, A. P. L., Marinho, R. R. B., \& Lima, E. K. N. S. (2021). Aplicação da ozonioterapia na odontologia: revisão integrativa. Revista Eletrônica Acervo Saúde, 13(8), e8648-e8648.

Fernandes, H., Gurgel, T. L. S., de Assis Costa, M. D. M., Júnior, J. J. V., Vianna, A. C. F., da Silva, G. R., \& Dietrich, L. (2019). OZONIOTERAPIA NO CONTROLE DE INFECÇÃO EM CIRURGIA ORAL. Revista de Odontologia Contemporânea, 3(1), 37-43.

GAO, L., Dou, J., Zhang, B., Zeng, J., Cheng, Q., Lei, L., Tan, L., Zeng, Q., Ding, S., Guo, A., Cheng, H., Yang, C., Luo, Z., Lu, J. Ozone therapy promotes the differentiation of basal keratinocytes via increasing Tp63-mediated transcription 
of KRT10 to improve psoriasis. J Cell Mol Med. n.24, v. 8, págs. 4819-4829, 2020 doi: $10.1111 / \mathrm{jcmm} .15160$.

GRILLO, R., Lacerda, A.C., de Barros, T.E.P., Jodas, C.R.P., Teixeira, R.G. Efficacy of biostimulatory ozone therapy: Case report and literature review. J Cosmet Dermatol. n. 19, 2021 doi: 10.1111/jocd.14079.

Libório, K. O., \& Dosea, R. R. (2020). Qualidade Pós-Operatória em Procedimento de Bichectomia Associada a Ozonioterapia. AESTHETIC OROFACIAL SCIENCE, $1(1), 52-61$.

Maia, M. E. N. D. C. (2017). Análise da qualidade da água na eficácia do vapor de ozônio na estética facial.

PEDERZOLI, P., Greco, Lucchina, A., Del, F.M., Mortellaro, C. Concentrated growth factors gel activated with ozone for facial aesthetics purpose after granuloma removal: a case report. J Biol Regul Homeost Agents. n. 35, v. 2, págs. 345-350, 2021 doi: 10.23812/21-2supp1-34.

Santos, A. C. S. V. D. (2018). Ozonioterapia como terapia adjunta à raspagem no tratamento periodontal de pacientes com Diabetes mellitus: série de casos.

TIRELLI, U., Cirrito, C., Pavanello, M., Piasentin, C., Lleshi, A., Taibi, R. Ozone therapy in 65 patients with fibromyalgia: an effective therapy. Eur Rev Med Pharmacol Sci. n. 23, v. 4, págs. 1786-1788, 2019 doi: 10.26355/eurrev_201902_17141.

XIAO, W., Tang, H., Wu, M., Liao, Y., Li, K., Li, L., Xu, X. Ozone oil promotes wound healing by increasing the migration of fibroblasts via PI3K/Akt/mTOR signaling pathway. Biosci Rep. n. 9, v. 6, 2017 doi: 10.1042/BSR20170658.

ZENG, J., Lu, J. Mechanisms of action involved in ozone-therapy in skin diseases. Int Immunopharmacol. n, 56, págs. 235-241, 2018 doi: 10.1016/j.intimp.2018.01.040.

ZENG1, J., Dou, J., Gao, L., Xiang, Y., Huang, J., Ding, S., Chen, J., Zeng, Q., Luo, Z., Tan, W., Lu, J. Topical ozone therapy restores microbiome diversity in atopic dermatitis. Int Immunopharmacol. n.80, e106191, 2020 doi: 10.1016/j.intimp.2020.106191.

ZENG2, J., Lei, L., Zeng, Q., Yao, Y., Wu, Y., Li, Q., Gao, L., Du, H., Xie, Y., Huang, J., Tan, W., Lu, J. Ozone Therapy Attenuates NF-кB-Mediated Local 
Inflammatory Response and Activation of Th17 Cells in Treatment for Psoriasis.

Int J Biol Sci. n. 6, n. 11, págs. 1833-1845, 2020 doi: 10.7150/ijbs.41940. 